\title{
Phase Stability of Water-Quenched U-6 wt.\% Nb Alloy During Low-Temperature Aging
}

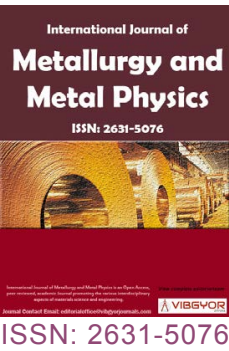

\section{LM Hsiung*}

\author{
Materials Science Division, Physical and Life Sciences Directorate, Lawrence Livermore National Laboratory, \\ USA
}

\begin{abstract}
TEM analyses, microhardness measurements, and tensile testing were carried out to investigate the microstructure and phase stability of a water-quenched (WQ) U- 6 wt.\% Nb alloy subjected to low-temperature aging experiments that include (i) $200{ }^{\circ} \mathrm{C}$ aging of as-water-quenched alloy, (ii) Ambient-temperature aging of WQ alloy for 15 years (i.e., 15-year-old WQ alloy), and (iii) Accelerated aging of 15 -year-old WQ alloy at $200^{\circ} \mathrm{C}$ and $212^{\circ} \mathrm{C}$. Age hardening occurred during the initial stages of $200^{\circ} \mathrm{C}$ aging of as-water-quenched alloy containing mainly an $\alpha$ " (monotonic) martensite. The microhardness continuously increased with aging time up to 8 hours because of the onset of a spinodal decomposition to form a modulated structure with the modulation wavelength $\sim 3 \mathrm{~nm}$ propagating along the [001] $\alpha^{\prime \prime}$ direction. A decrease in microhardness occurred when coarsening of the modulated structure took place after thermally aged for more than 8 hours. TEM observations of swirl-shape antiphase domain boundaries (APBs) formed in the 15-year-old WQ alloy, however, revealed the occurrence of a chemical-ordering reaction in the $\alpha^{\prime \prime}$ (monotonic) martensite. The chemical ordering reaction can be attributed to the development of a composition fluctuation with the wavelength $\sim 0.5 \mathrm{~nm}$ propagating along the [001] $\alpha$ " direction. As a result of the chemical ordering, the 15-year-old WQ alloy revealed an aging behavior distinctly different from that of the as-water-quenched alloy during low-temperature aging. The microhardness continuously increased to much higher values after prolonged aging up to 240 hours at $200{ }^{\circ} \mathrm{C}$ and 96 hours at $212{ }^{\circ} \mathrm{C}$. The accelerated aging of the 15 -year-old WQ alloy resulted in the decomposition of the chemically ordered $\alpha^{\prime \prime}$ martensite into a $\mathrm{Nb}$-depleted $\alpha$ (orthorhombic) phase and a $\mathrm{Nb}$-enriched ordered phase, which resulted in precipitation hardening and gave rise to a significant ductility reduction. Aging mechanisms and transformation sequences are accordingly proposed to depict the phase stability of WQ-U6Nb alloy during low-temperature aging.
\end{abstract}

\section{Introduction}

It is known that uranium-niobium alloys, as exploited for a variety of engineering and structural applications, has a microstructure containing martensitic phases supersaturated with $\mathrm{Nb}$ that can be obtained by rapid quenching the alloy from $\gamma$ (bcc)-field solid solution to room temperature $[1,2]$. U-6 wt.\% Nb alloy contains approximately 14 atomic percent of niobium that is close to the monotectoid composition (13.3 at.\% Nb). At temperatures

*Corresponding author: LM Hsiung, Materials Science Division, Physical and Life Sciences Directorate, Lawrence Livermore National Laboratory, Livermore, CA 94550, California, USA

Accepted: September 05, 2019; Published: September 07, 2019

Copyright: (C) 2019 Hsiung LM. This is an open-access article distributed under the terms of the Creative Commons Attribution License, which permits unrestricted use, distribution, and reproduction in any medium, provided the original author and source are credited.

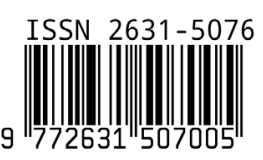

Hsiung. Int J Metall Met Phys 2019, 4:038 
above $647^{\circ} \mathrm{C}$, the equilibrium phase is a $\gamma$ phase [body-centered cubic (bcc); $a=0.3347 \mathrm{~nm}$ ]. A water-quenched U-6 wt.\% Nb (WQ-U6Nb) from the $\gamma$ (bcc)-field solid solution has a microstructure containing martensitic phases that are supersaturated with 14 at.\% Nb. It is worth noting that the crystal lattice of supersaturated solid solution formed by rapid quenching is unstable and is severely distorted since the solubility of $\mathrm{Nb}$ in the $\alpha$ phase (orthorhombic; $a=0.285 \mathrm{~nm}, \mathrm{~b}=0.5861 \mathrm{~nm}, \mathrm{c}=0.4947$ $\mathrm{nm}$ ) at room temperature is nearly zero in stable equilibrium [1]. In the stresses-induced martensitic transformation, a variant of the low-temperature orthorhombic $(\alpha)$ phase is usually formed. This phase is designated $\alpha^{\prime}$ martensite since its lattice parameters (orthorhombic; $a=0.285 \mathrm{~nm}, b=0.5802$ $\mathrm{nm}, \mathrm{c}=0.4988 \mathrm{~nm}$ ) differ from the equilibrium $\alpha$ phase. Two additional variant phases, a monoclinic distortion of $\alpha^{\prime}$, named $\alpha^{\prime \prime}$ martensite (monoclinic; $a=0.285 \mathrm{~nm}, b=0.576 \mathrm{~nm}, c=0.4997 \mathrm{~nm}, \gamma$ $=91.3^{\circ}$ ), or a tetragonal distortion of $\gamma$, named $\gamma^{\circ}$ martensite (tetragonal; $a=b=0.701 \mathrm{~nm}, c=0.674$ $\mathrm{nm}$ ), can also form WQ-U6Nb alloy. The WQ-U6Nb alloy has improved mechanical properties (ductility and toughness) $[3,4]$ and excellent corrosion resistance $[2,5]$ because of the uniform distribution of niobium atoms in the solid solution that suppresses the diffusional decomposition reaction to form a two-phase ( $\mathrm{Nb}$-depleted $\alpha$ phase and $\mathrm{Nb}$-enriched $\checkmark$ phase) cellular microstructure. It is also known that the water-quenched U6Nb alloy containing $\alpha^{\prime \prime}$ martensite, which consists of many different variants of fine twins, reveals shape memory effect that results in low yield strength ( $200 \mathrm{MPa})$ and high tensile ductility ( $\geq 30 \%)[2,6,7]$. Thermal aging of the $\alpha^{\prime \prime}$ martensite in a temperature ranging from $250{ }^{\circ} \mathrm{C}$ to $400{ }^{\circ} \mathrm{C}$ resulted in an increase of yield strength $[3,4,8,9]$. Using Atom Probe Field Ion Microscopy (APFIM) method, Beverini and Edmonds [4] found an age hardening/softening phenomenon associated with nanometer length-scale of segregation reaction presumably due to spinodal decomposition [10]. According to their investigation, an age hardening/softening phenomenon associated with nanoscale solute segregation presumably caused by spinodal decomposition was detected. In the alloy samples aged at $300{ }^{\circ} \mathrm{C}$ for 16 hours, $\mathrm{Nb}$ content was fluctuated between 5 at.\% and 30 at.\%, and the wavelength of the composition fluctuation was reported to be about $3 \mathrm{~nm}$. Preliminary TEM analyses that clarified the formation of fine- scale modulated microstructure due to spinodal decomposition in WQ-U6Nb thermally aged at 200 ${ }^{\circ} \mathrm{C}$ were reported by Zhou and Hsiung [11]. Note that spinodal decomposition is a continuous transformation mechanism in which the supersaturated solid solution separates spontaneously into solute-lean and solute-rich phases within the parent phase-domain through uphill diffusion [12]. It is a phase transient mechanism leading to aging hardening and subsequent softening when the modulated structure becomes coarsened.

The structural components made of WQ-U6Nb alloy have been in service for more than two decades. The main concerns with these components are how the microstructure and mechanical properties have changed, and how will these changes proceed in the future. To address these issues, there is a need to know how the microstructure has been evolved since the alloy was fabricated and put into service decades ago. There is also a need to know how the microstructure evolution will affect the mechanical stability. In this study, aging behavior of as-water-quenched alloy thermally aged at $200{ }^{\circ} \mathrm{C}$ was investigated to compare with the age behavior of 15 -year-old $W Q$ alloy thermally aged at temperatures below $250{ }^{\circ} \mathrm{C}$. The emphasis has been placed on the low-temperature aging mechanisms of WQ-U6Nb alloy.

\section{Experimental}

The U6Nb alloy used for this investigation was wrought-processed from Rocky Flats VAR VAR ingot at the BWXT/Bechtel Y-12 plant. The detailed information regarding the fabrication process can be found in Ref. [2]. As-water-quenched U6Nb alloy samples were obtained by solution-treating the wrought $U 6 \mathrm{Nb}$ alloy at $800{ }^{\circ} \mathrm{C}$ for 4 hours followed by quench in water. The WQ-U6Nb alloy samples naturally aged at ambient temperatures for 15 years (designated as 15-year-old WQ alloy hereafter) were machined directly from a $38-\mathrm{mm}$ thick plate. Rod-shaped specimens of $3 \mathrm{~mm}$ in diameter were prepared for microstructure analyses. Aging experiments of both as-water-quenched and 15 -year-old alloy samples were carried out at 200 ${ }^{\circ} \mathrm{C}$ and $212{ }^{\circ} \mathrm{C}$ in a vacuum furnace. Microhardness measurements were performed on all these samples using a Vickers-hardness indenter. This was conducted to monitor the change of mechanical property during aging processes. The applied load was $50 \mathrm{~g}$, and the time-duration was 35 seconds for 


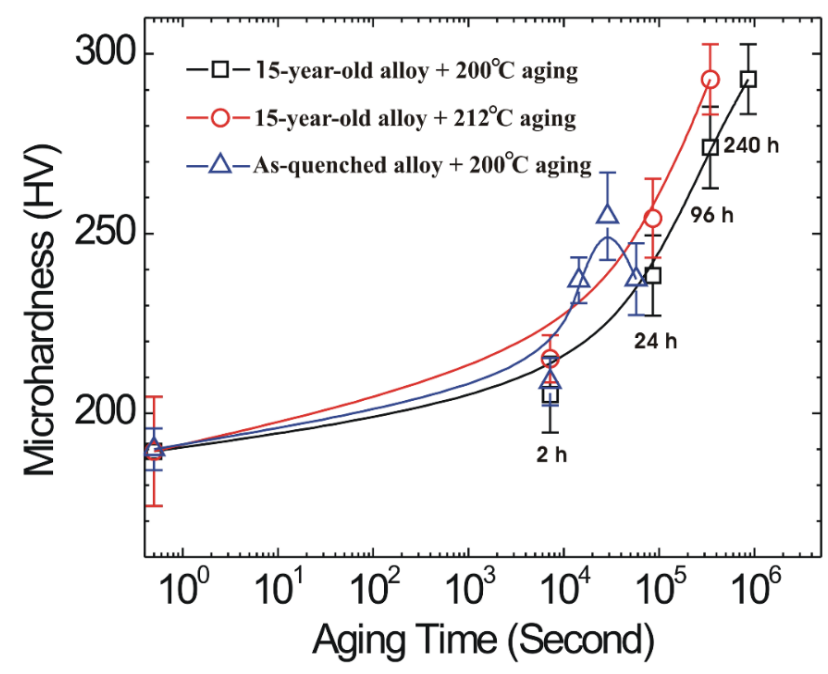

Figure 1: Changes of microhardness for thermal aging of the as-water-quenched alloy at $200{ }^{\circ} \mathrm{C}$ and the 15 -year-old WQ alloy at $200{ }^{\circ} \mathrm{C}$ and $212^{\circ} \mathrm{C}$.

each test. To obtain a statistically significant value, more than six tests were conducted for each measurement. Tensile tests were performed in air at room temperature with an INSTRON survo-hydraulic testing machine. Dog-bone shape specimens with gauge dimensions of $6.4 \times 1.0 \times 19 \mathrm{~mm}$ were used for tensile elongation tests. The amount of strain was measured with a clip-on extensometer. All the tests were employed a constant strainrate of $1 \times 10^{-3} \mathrm{sec}^{-1}$ and were terminated when the specimen fractured in the gauge section. Tensile tests were performed in air at room temperature with an INSTRON survo-hydraulic testing machine. Dog-bone shape specimens with gauge dimensions of $6.4 \times 1.0 \times 19 \mathrm{~mm}$ were used for tensile elongation tests. The amount of strain was measured with a clip-on extensometer. All the tests were employed a constant strain-rate of $1 \times 10^{-3} \mathrm{sec}^{-1}$ and were terminated when the specimen fractured in the gauge section. The microstructures of an aswater-quenched alloy, WQ plus thermally aged alloy, WQ plus natural aging, and thermal aging of naturally aged alloy were examined using a JEOL200CX transmission electron microscope. TEM foils were machined from the rod-shape samples, and the final thinning of the foils was prepared by twinjet electropolishing in a solution of 45 vol.\% methanol, 45 vol.\% butyl alcohol, and 10 vol.\% nitric acid at $50 \mathrm{~V}$ and $-20{ }^{\circ} \mathrm{C}$. It is worth noting that all TEM foils examined were immersed in ethanol after electro-polishing and then were loaded into sample stage of the microscope to minimize the con- tamination of thin foils due to surface oxidation. A computer package, CaRIne Crystallography, was utilized to simulate electron diffraction patterns for the assistance of phase identification.

\section{Experimental Results}

The result of microhardness (in HV unit) measured from as-water-quenched alloy samples thermally aged at $200^{\circ} \mathrm{C}$ is shown in Figure 1 , in which the results of microhardness measured from accelerated heating of the 15 -year-old WQ alloy samples at $200{ }^{\circ} \mathrm{C}$ and $212{ }^{\circ} \mathrm{C}$ are also shown for a comparison. Age hardening can be clearly seen from both as-water-quenched and 15-year-old WQ alloy samples because of the thermal aging. However, distinctly different aging behaviors are shown between the as-water-quenched and the 15-year-old WQ alloy samples. Unlike the as-water-quenched alloy that reached peak hardness after heating for 8 hours, the microhardness of 15 -year-old WQ alloy continuously increased even after prolonged aging with the microhardness increasing to a much greater value compared to that of the as-waterquenched alloy. The different aging behaviors suggest that different aging mechanisms take place in the as-water-quenched and the 15-year-old WQ alloys, which will be further elucidated below.

\section{Thermal aging of as-water-quenched $\mathrm{U} 6 \mathrm{Nb}$ at $200{ }^{\circ} \mathrm{C}$}

The as-water-quenched alloy had an average microhardness (in HV unit) of 190. The microhardness value increased to 210 after thermal aging for 2 hours, increased to 237 after thermal aging for 4 hours, and increased to 254.8 after thermal aging for 8 hours. Within the first 8 hours of aging, the strengthening continued but with a decreasing trend. Further aging caused softening after the microhardness reached a maximum value at 8 hours, and the microhardness reduced to 237 at 16 hours. While no notable change of the lamellar microstructure of $\alpha^{\prime \prime}$ martensite can be found from the low-magnification images shown in Figure 2, a modulated structure of dark/bright fringes in association with satellite spots excited on either side of the main Bragg diffraction spots can be readily seen in the high-magnification phase-contrast images shown in Figure 3, which verify the occurrence of spinodal decomposition. The modulation formed because of the wave of $\mathrm{Nb}$ fluctuation with a wavelength of $3 \mathrm{~nm}$ propagating predominantly 

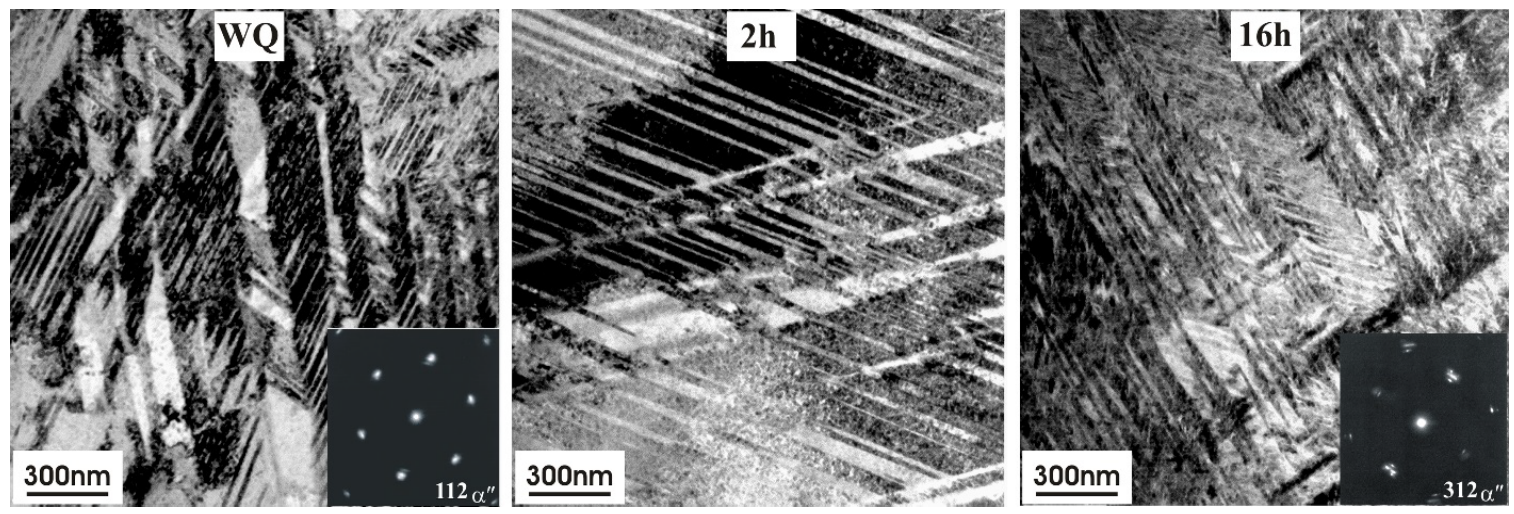

Figure 2: Low-magnification TEM images show the lamellar microstructure of $\alpha^{\prime \prime}$ martensite in the as-waterquenched (WQ) alloy and in the alloy samples after thermally aged at $200{ }^{\circ} \mathrm{C}$ for 2 hours ( $2 \mathrm{~h}$ ) and 16 hours (16 h). Selected-area diffraction (SAD) patterns of the [112] ${ }_{\alpha^{\prime \prime}}$ - and [312] ${ }_{\alpha^{\prime \prime}}$-zone were inserted to demonstrate the existence of $\alpha^{\prime \prime}$ phase in the WQ and the $16 \mathrm{~h}$ alloy samples.
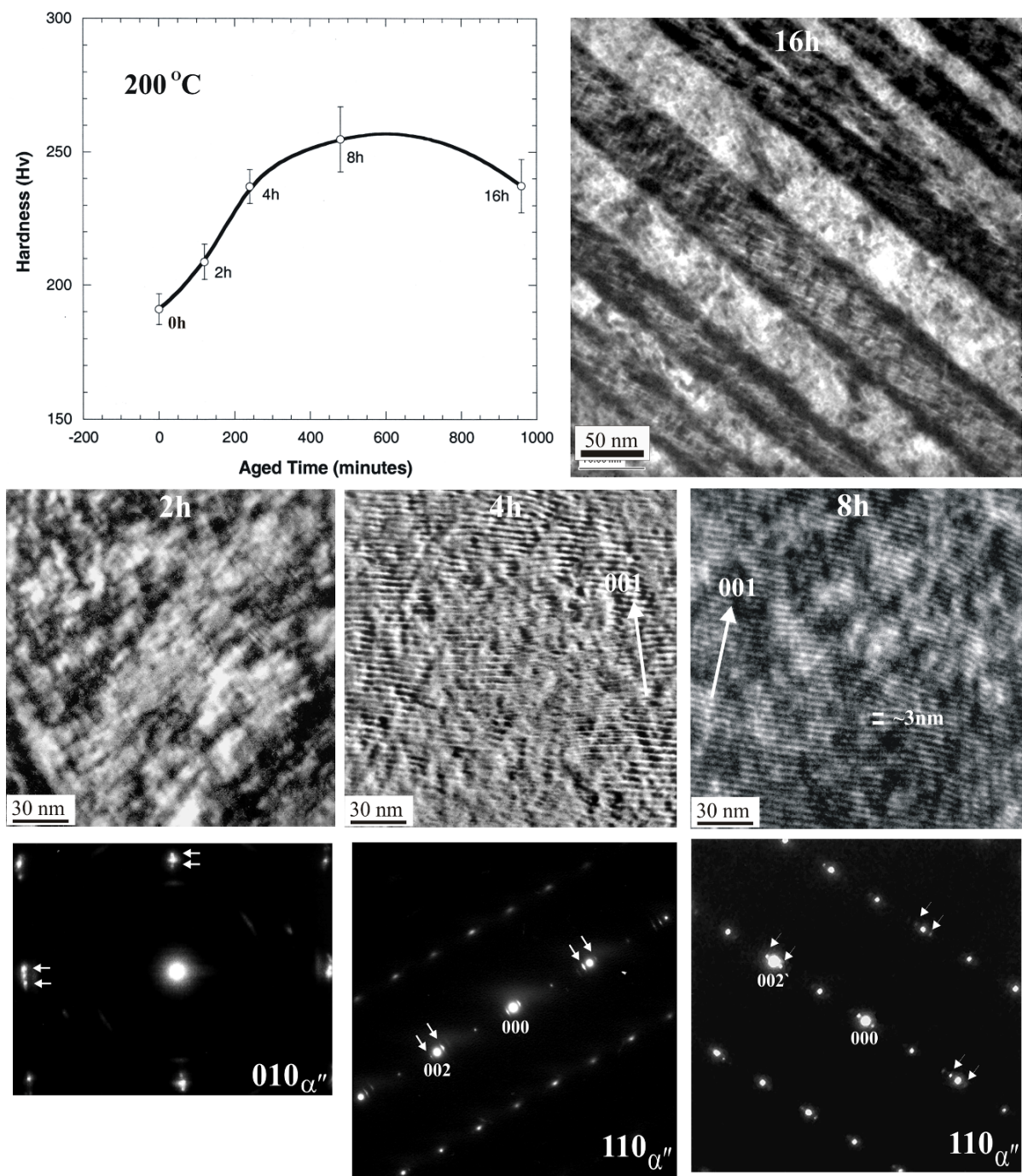

Figure 3: Phase-contrast TEM images show the development of a modulated structure in WQ-U6Nb after thermally aged at $200^{\circ} \mathrm{C}$ for 2 hours ( $\left.2 \mathrm{~h}\right), 4$ hours $(4 \mathrm{~h}), 8$ hours $(8 \mathrm{~h})$, and 16 hours (16 h). Satellite diffraction spots arising from the modulated structure with the wavelength of $3 \mathrm{~nm}$ are marked by arrows shown in the $[010]_{\alpha^{\prime}}$ and [110] ${ }_{\alpha^{\prime \prime}}$-zone diffraction patterns generated from the $2 \mathrm{~h}$, the $4 \mathrm{~h}$, and the $8 \mathrm{~h}$ samples. Coarsening of the modulated structure was observed from the $16 \mathrm{~h}$ sample. 


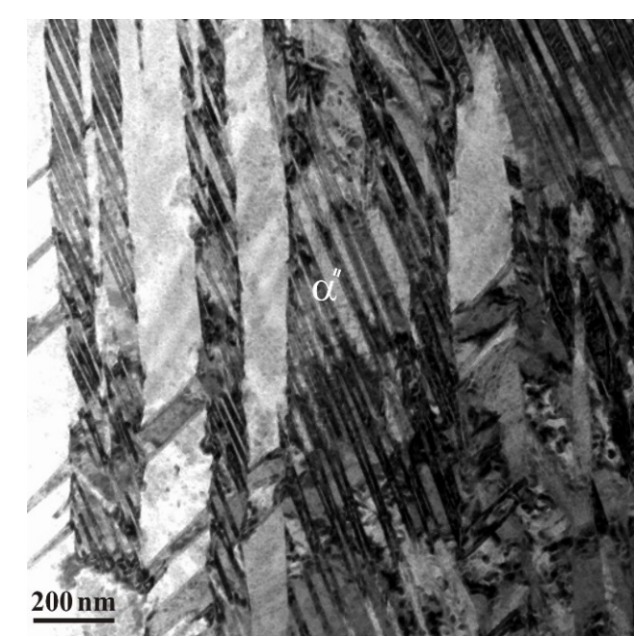

(a)

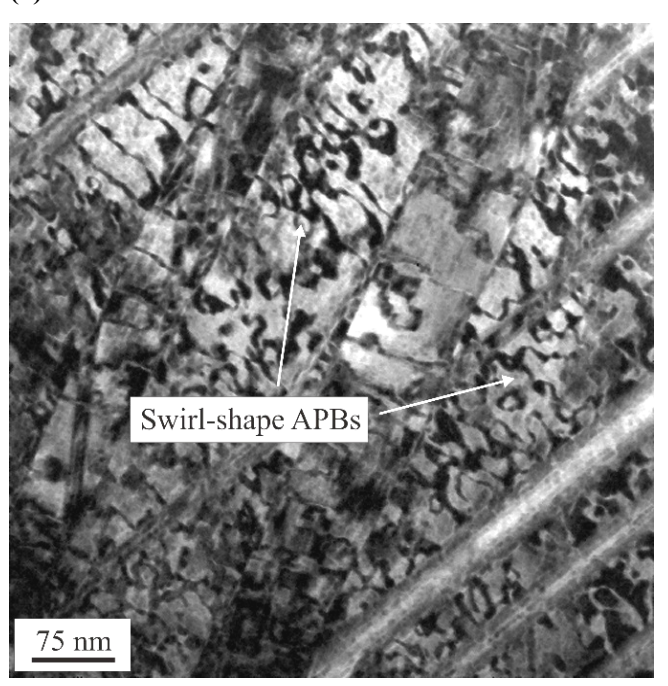

(b)

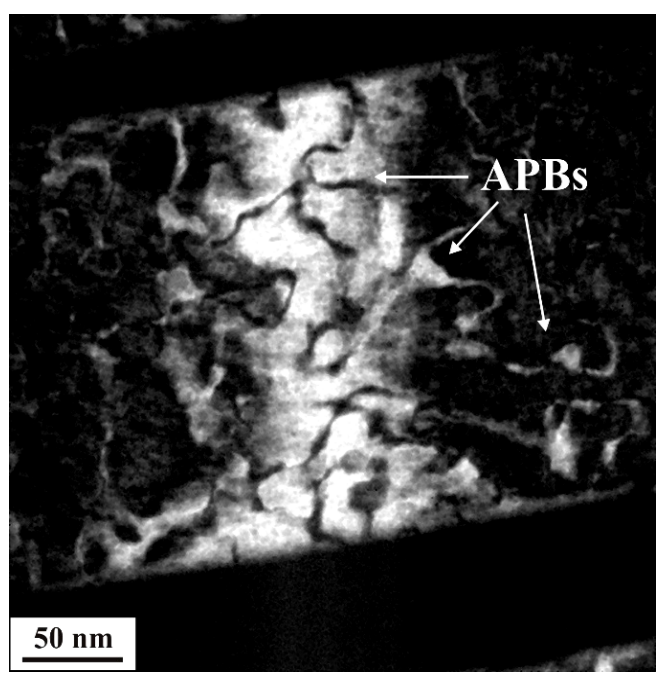

(c)

Figure 4: a) Low magnification bright field TEM images show a lamellar structure of the $\alpha^{\prime \prime}$ martensite in 15-year-old WQ-U6Nb. High magnification brightfield; b) And dark-field; c) TEM images show swirlshape antiphase domain boundaries (APBs) in the 15-year-old WQ alloy. along the elastically softest direction: The $[001]_{\alpha^{\prime \prime}}$ direction. As a result, the modulated structure contains $\mathrm{Nb}$-lean and $\mathrm{Nb}$-enriched phase-domains of 3 $\mathrm{nm}$ thick accompanied with satellite reflections in electron diffraction patterns can be observed using TEM techniques [13]. The satellite diffraction spots formed in the direction of modulation because of the contribution of lattice parameter variation [14]. After the modulated structure was fully developed at 8 hours, further thermal aging led to coarsening of the modulated structure and decrease in microhardness.

\section{Ambient-temperature aging of WQ-U6Nb for 15 years}

Chemical ordering of the $\alpha^{\prime \prime}$ martensite in the 15-year-old WQ alloy was clarified using TEM phase analysis and electron diffraction techniques. Like the as-water-quenched alloy, the lamellar microstructure of $\alpha^{\prime \prime}$ martensite in the 15-year-old WQ alloy remained no change, as shown in Figure 4a. However, a unique feature observed from the 15-year-old alloy is the formation of swirl-shape antiphase domain boundaries (APBs) shown in Figure $4 \mathrm{~b}$ and Figure $4 \mathrm{c}$. As will be demonstrated later that the APBs (also known as $\pi$ boundaries) can be verified based on the following visibility criteria: The contrast of APBs is visible when the phase angle $\alpha=2 \pi g \bullet P=\pi$ is invisible when $\alpha=2 \pi$ (where $\mathbf{g}$ is the reflection vector for imaging, and $\mathbf{P}$ is the displacement vector of APB) [13]. The observation of swirl-shape APBs in the 15-year-old alloy reveals a continuous order-disorder transition takes place in the $\alpha^{\prime \prime}$ martensite. Since the ordering transition occurs at ambient temperatures, crystal structure of the ordered $\alpha^{\prime \prime}$ martensitic phase likely remains monotonic as that of the disordered $\alpha^{\prime \prime}$ martensitic phase except that the unit cell takes up a superlattice arrangement due to the occupation of lattice sites by specific atom species. An APB is produced by an antiphase vector $P$ which brings about the displacement of one atomic species from on sublattice to another. Crystal structure of the ordered $\alpha^{\prime \prime}$ martensitic phase can therefore be identified using TEM phase-analysis method by matching the observed and simulated diffraction patterns.

To explain the formation of APBs in the 15-yearold WQ alloy, a chemically ordered $\alpha^{\prime \prime}$ martensitic phase is accordingly proposed. The existence of ordered $\alpha^{\prime \prime}$ phase can be verified by matching the observed diffraction pattern with the simulat- 


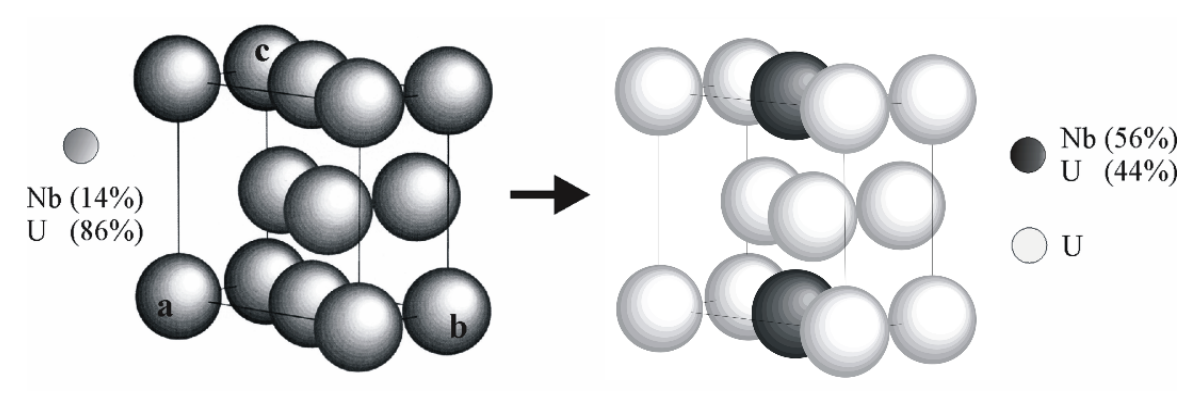

(a)

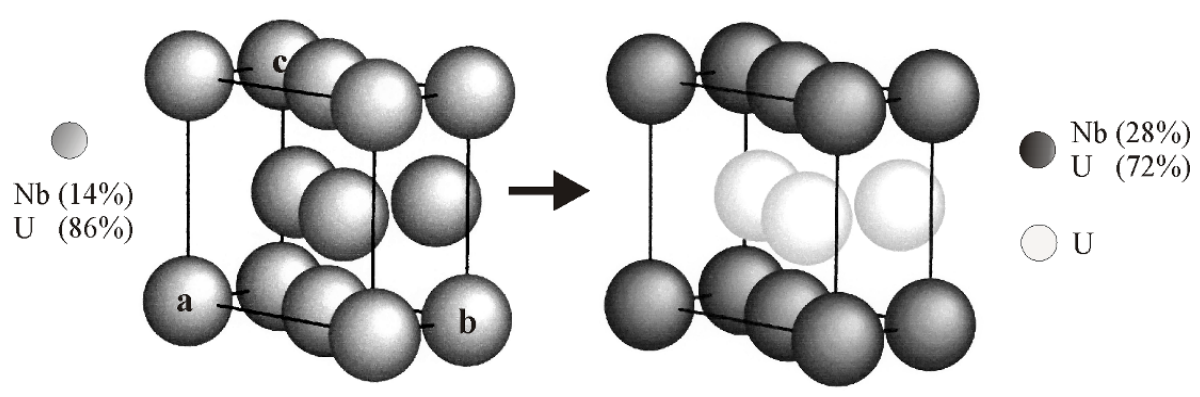

(b)

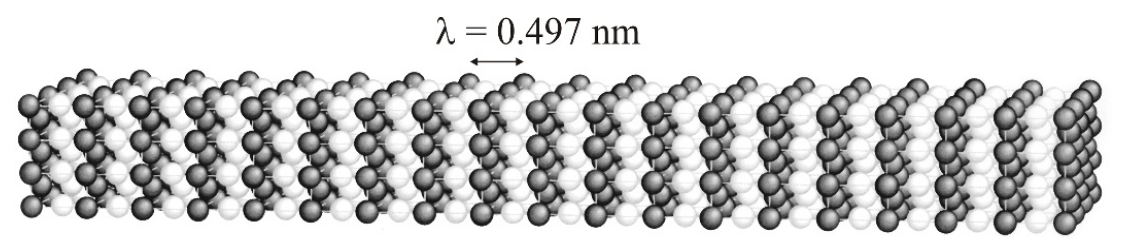

(c)

Figure 5: Two proposed schemes of chemical ordering taken place in the 15-year-old U6Nb: a) Scheme I and b) Scheme II; c) Scheme II ordered superlattice can be regarded because of a spinodal modulation from which the $\mathrm{Nb}$ content fluctuates between 0 and 28 at.\% and the wavelength $(\lambda)$ of the composition fluctuation is equal to the lattice parameter of the ordered $\alpha^{\prime \prime}$ unit cell in the [001] direction, i.e. $\lambda=0.497 \mathrm{~nm}$.

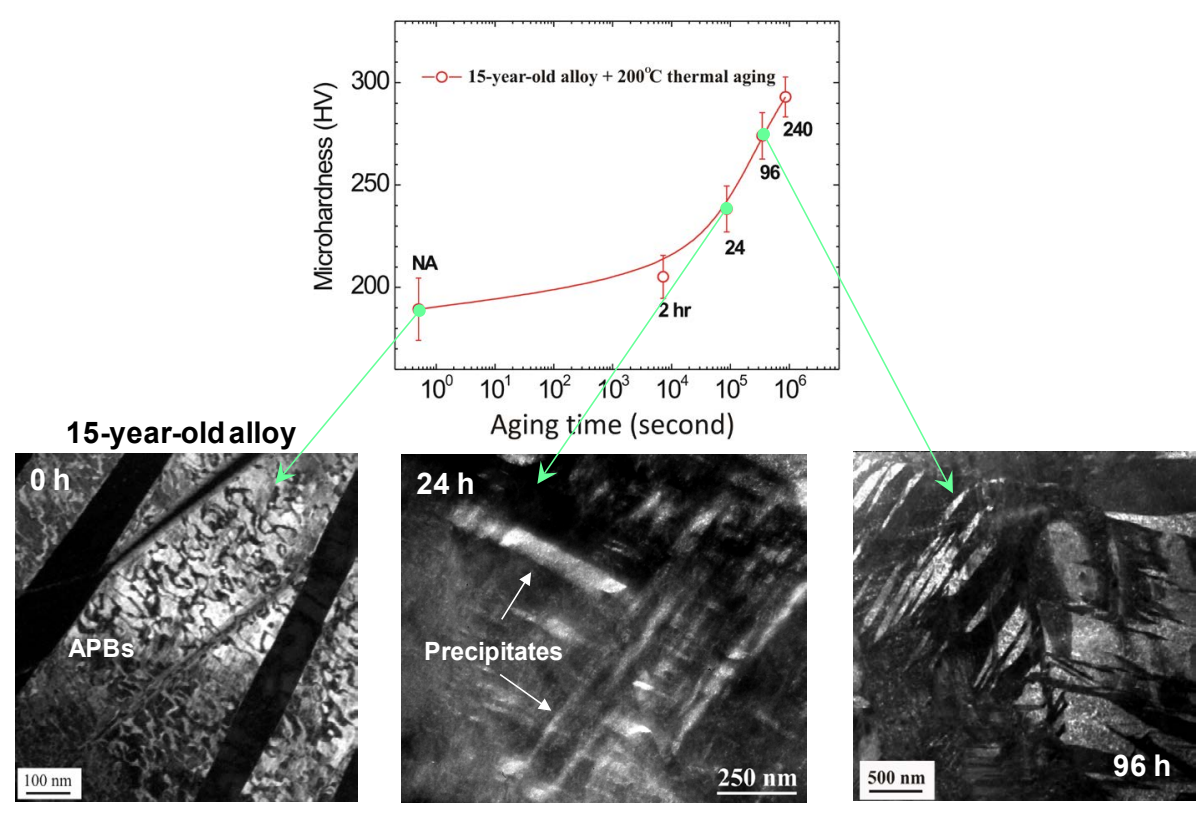

Figure 6: Microhardness variation: a) And microstructure evolution; b,c,d) Of the 15-year-old WQ alloy thermally aged at $200{ }^{\circ} \mathrm{C}$ up to 240 hours. 
ed diffraction patterns generated according to the proposed superlattice structures. Figure 5 illustrates two possible schemes for the order-disorder transition in the supersaturated $\alpha^{\prime \prime}$ solid solution with a mean concentration $c_{o}=14$ at. $\%$ Nb. Here, the probability of random site occupancy on each atomic site of the disordered $\alpha^{\prime \prime}$ unit cell (monoclinic; $a=0.285 \mathrm{~nm}, b=0.576 \mathrm{~nm}, c=0.4997 \mathrm{~nm}$, $\gamma=91.3^{\circ} ; 4$ lattice sites/unit cell) by $U$ and $\mathrm{Nb}$ is $86 \%$ and $14 \%$, respectively. Note that for the con-

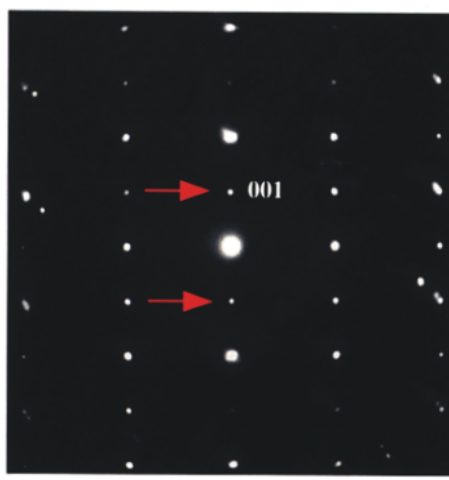

[110]

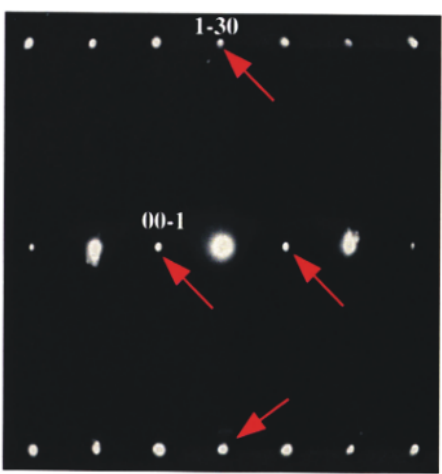

[310]

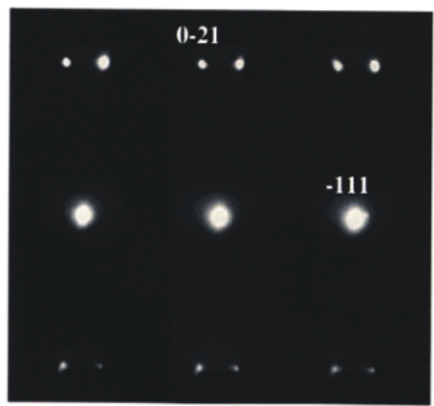

[312]
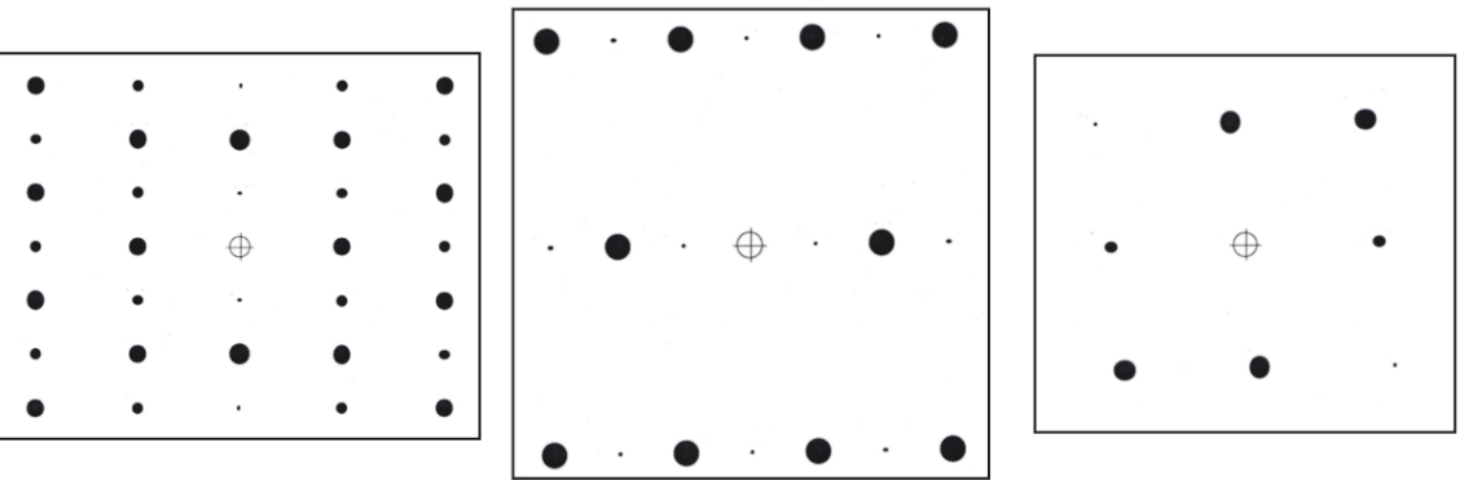

(a)

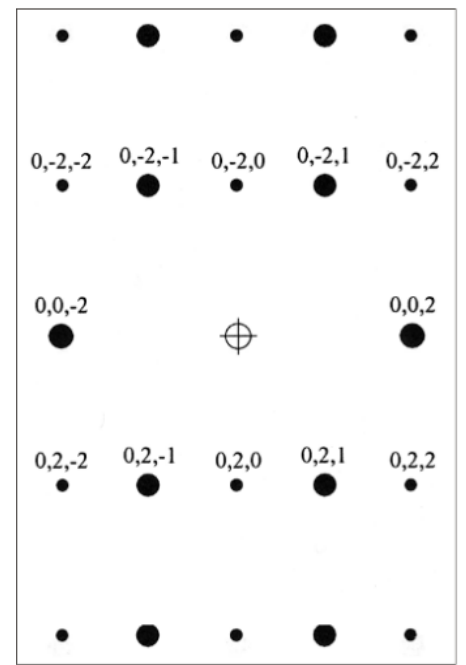

Disordered $\alpha^{\prime \prime}$

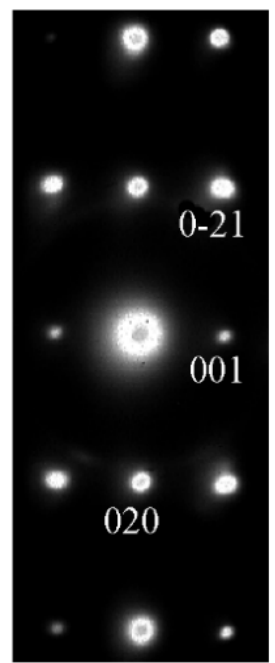

$[100]$

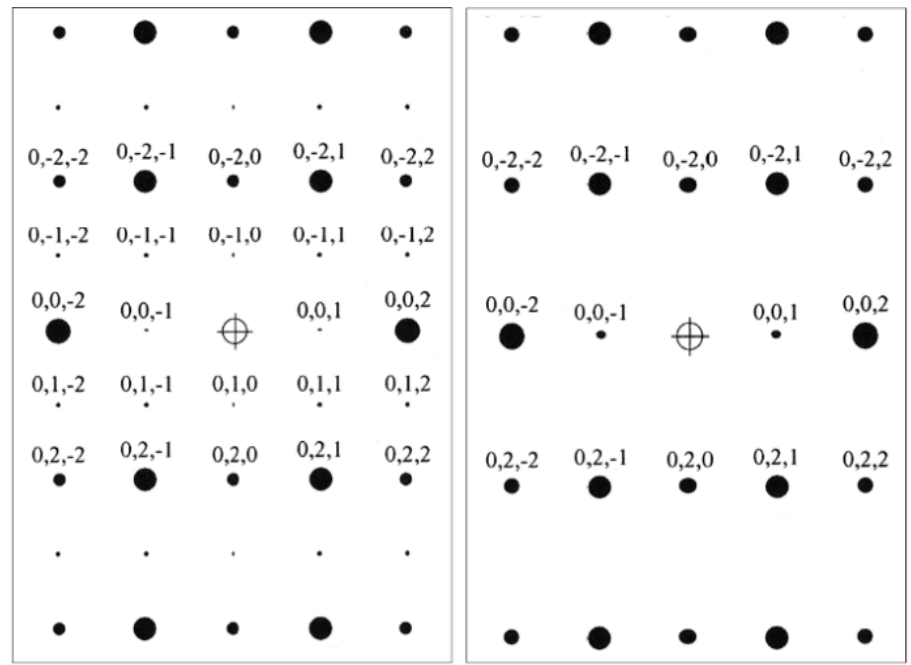

Scheme I
Scheme II

(b)

Figure 7: Phase analysis of the ordered phase that revealed the swirl-shaped APB in the 15-year-old WQU6Nb: a) Scheme I and Scheme II have the same selected-area diffraction (SAD) patterns of the [110]-, the [310]-, and the [312]-zone; b) Simulated diffraction pattern of Scheme II is a better match with the SAD pattern of the [100]-zone. 
venience of viewing purpose, the unit cell is illustrated herewith the coordinate origin $(0,0,0)$ locating at an atomic site. For the partially ordered superlattice structure of Scheme I, as illustrated in Figure $6 a$, the following three lattice sites $(0,0,0)$, $(0,5 / 6,1 / 2)$, and $(1 / 2,1 / 3,1 / 2)$ are occupied solely by $U$ atoms, and the $(1 / 2,1 / 2,0)$ lattice site is randomly occupied by $\mathrm{U}$ and $\mathrm{Nb}$ atoms. For the partially ordered superlattice of Scheme II, as illustrated in Figure $6 b$, the $(0,5 / 6,1 / 2)$ and $(1 / 2,1 / 3,1 / 2)$ lattice sites are occupied solely by $U$ atoms, the $(0,0,0)$ and $(1 / 2,1 / 2,0)$ lattice sites are randomly occupied by $U$ and $\mathrm{Nb}$ atoms, and the probability of site occupancy by $\mathrm{U}$ and $\mathrm{Nb}$ are $72 \%$ and $28 \%$, respectively. The systematic variations in the atomic positions result in different ordered domains separated by APBs across which the atoms have the wrong immediate neighbors. Note that Scheme II ordering transition can also be regarded as a spinodal decomposition in which the $\mathrm{Nb}$ content fluctuates between 0 and 28 at. \% (i.e., $c_{o} \pm \delta c$, and $\delta c=14$ at.\%), and the wavelength $(\lambda)$ of composition fluctuation is equal to the lattice parameter of the ordered $\alpha^{\prime \prime}$ unit cell in the [001] direction, i.e. $\lambda=0.495 \mathrm{~nm}$, which is an order of magnitude smaller than the wavelength of spinodal decomposition observed in new WQ alloy aged at $200^{\circ} \mathrm{C}$. This type of ordering transition without a change of composition resulting from the composition fluctuation with the wavelength equal to that of the interatomic spacing is termed as continuous ordering [15]. Like the spinodal decomposition, the continuous ordering is solely a diffusion reaction involving atoms exchanging lattice sites, and the parent and product phase share a common crystal lattice.

Selected-area diffraction (SAD) patterns of the [110]-, the [310]-, the [312]-, and the [100]-zone observed from a 15-year-old WQ alloy sample are shown in Figure 7, in which the simulated diffraction patterns of these three zones are also displayed. While the simulated diffraction patterns of the [110]-, the [310]-, and the [312]-zone (see Figure 7a) show no difference between Scheme I and Scheme II superlattices, the simulated diffraction patterns of the [001]-zone are different between Scheme I and Scheme II superlattices (see Figure $7 b)$. The structure of ordered $\alpha^{\prime \prime}$ martensitic phase is thus identified to be of Scheme II by matching the observed and simulated [100]-zone diffraction patterns. An image-contrast analysis was conducted to verify the APBs formed in the 15-year-old alloy, and the result is shown in Figure 8. Here, the APBs are visible when $00 \overline{1}$ and $0 \overline{2} \overline{1}$ superlattice reflections were used for imaging but become invisible when $0 \overline{2} 0$ fundamental reflection was used for imaging. The observation and contrast analysis of swirl-shaped antiphase domain boundaries (APBs) are demonstrated in Figure 8. The contrast of antiphase domain boundary (also known as $\pi$ boundary) is visible when the phase angle $\alpha=2 \pi \mathbf{g} \cdot \mathbf{P}=$ $\pi$ and is invisible when $\alpha=2 \pi$ (where $g$ is the reflection vector for imaging, and $\mathbf{P}=1 / 2<011\rangle$ is the displacement vector of $\mathrm{APB}$ ). The bright-field (BF) image shown in Figure 8 clearly displays the swirl-shape feature of APBs. The APBs are visible in the dark-field images (DF-a and DF-b) obtained using the $0 \overline{2} \overline{1}$ and the $00 \overline{1}$ superlattice reflections, respectively. However, the APBs become invisible in the dark-field image (DF-c) obtained using the 0 $\overline{2} 0$ fundamental reflection. The formation of APBs reveals the occurrence of an ordering transformation, which leads to the formation of chemically ordered domains within the 15-year-old alloy. The ordered phase domain has the same crystal structure as that of the disordered phase domain, except it takes up a superlattice arrangement because of the periodic occupation of lattice sites by specific atom species.

\section{Accelerated aging of 15-year-old WQ-U6Nb at $200{ }^{\circ} \mathrm{C}$ and $212^{\circ} \mathrm{C}$}

To accelerate the on-going chemical ordering of the 15-year-old WQ alloy, thermal aging experiments were carried out at $200{ }^{\circ} \mathrm{C}$ and $212{ }^{\circ} \mathrm{C}$. The changes of microhardness with different aging durations are shown in Figure 1 to compare with the microhardness changes of the as-water-quenched alloy thermally aged at $200^{\circ} \mathrm{C}$. Notice that the initial microhardness of the 15 -year-old alloy sample had a value of 189.4, which is about the same value as that of the as-water-quenched alloy. This suggests that the 15-year natural aging of WQ-U6Nb at ambient temperatures hadn't caused any noticeable change in mechanical property. However, age hardening occurred, and the microhardness continuously increased to 292.5 whence the 15 -year-old WQ alloy was acceleratedly aged at $200{ }^{\circ} \mathrm{C}$ for 240 hours. It took only 96 hours to reach 292.5 whence the 15-year-old alloy acceleratedly aged at 212 ${ }^{\circ} \mathrm{C}$ because of increasing age-hardening rate. It is worth noting that the microhardness does not de- 

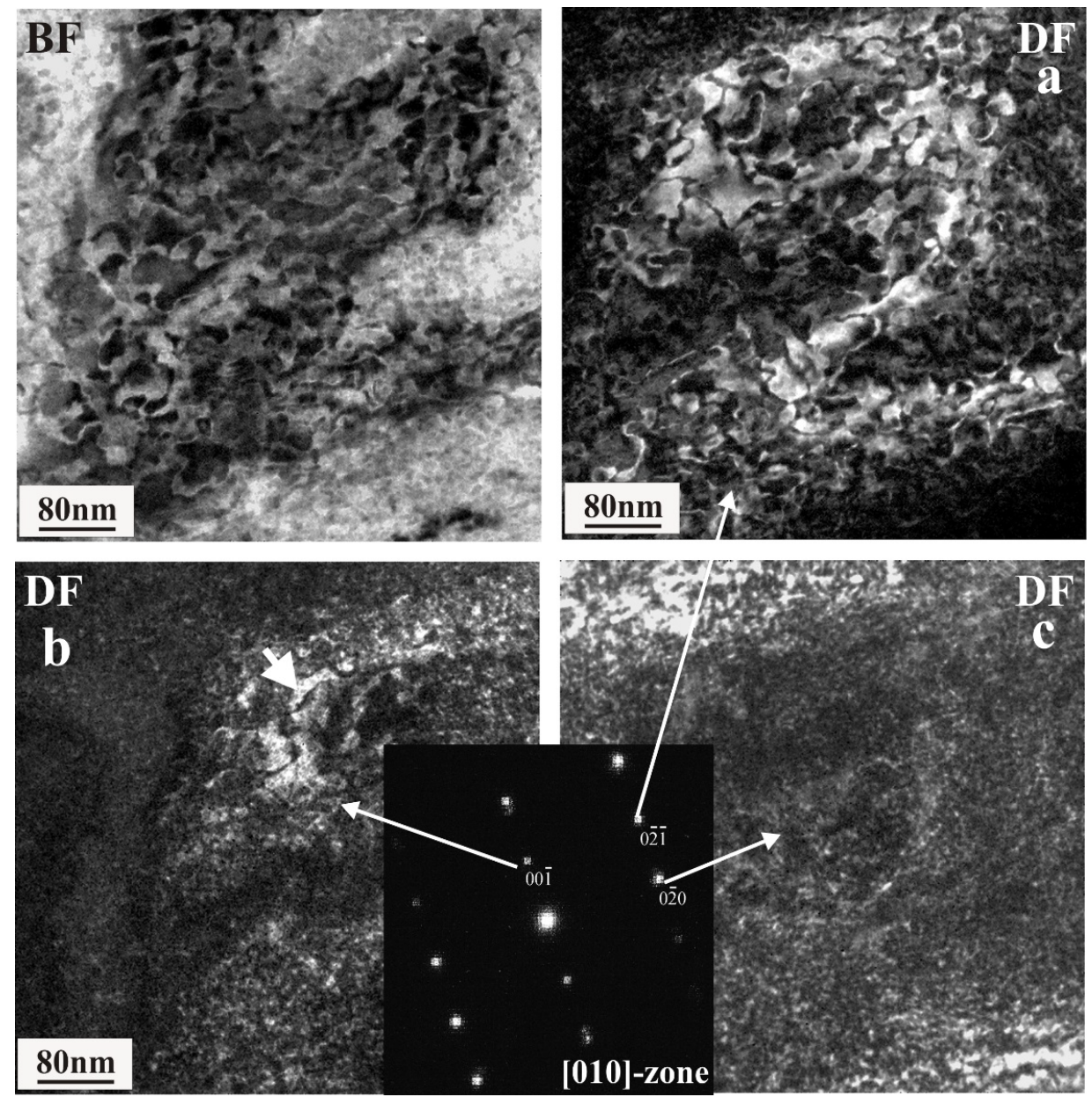

Figure 8: Bright-field (BF) and dark-field (DF) TEM images observed from the same area of the 15-year-old alloy sample. The swirl-shape APBs are visible in the DF images obtained using: $a, b)$ The $0 \overline{2} \overline{1}$ and the 00 $\overline{2}$ superlattice reflections but become invisible in the DF image obtained using; c) The $0 \overline{2} 0$ fundamental reflection.

crease even after thermal aging at $200{ }^{\circ} \mathrm{C}$ for 240 hours, which is significantly different from thermal aging of the as-water-quenched alloy: The microhardness starts to decrease after thermal aging at $200{ }^{\circ} \mathrm{C}$ for longer than 8 hours.

Microstructure evolution and microhardness variation of the 15 -year-old WQ alloy thermally aged at $200{ }^{\circ} \mathrm{C}$ up to 240 hours are shown in Figure 6. Notice that the swirl-shape APBs formed in 15-year-old WQ alloy (Figure 6a) no longer exist after thermal aging at $200{ }^{\circ} \mathrm{C}$; age hardening caused by the increasing volume fraction of plate-like precipitates can be clearly seen in $24 \mathrm{~h}$ (Figure 6b) and $96 \mathrm{~h}$ (Figure 6c) alloy samples. The occurrence of precipitation hardening in 15-year-old WQ alloy at 200 and $212{ }^{\circ} \mathrm{C}$ suggests that the sluggish on-going ordering transition at ambient temperatures kinetically accelerates whence thermal aging at 200 and $212{ }^{\circ} \mathrm{C}$. The crystal structure of the ordered precip- itates likely remains monotonic as that of the parent $\alpha^{\prime \prime}$ martensitic phase except that the unit cell takes up a superlattice arrangement. TEM phase analysis was accordingly conducted to identify the crystal structure of ordered precipitates. Typical selected-area electron diffraction (SAD) patterns of the [010]-, the [001]-, and the [110]-zone are presented in Figures 9a, Figures $9 b$ and Figures 9c. The SAD patterns match very well with the simulated diffraction patterns generated from a $\mathrm{Nb}$-depleted $\alpha(U)$ phase and the simulated diffraction patterns generated based on an ordered $\mathrm{U}_{3} \mathrm{Nb}(25$ at. \% $\mathrm{Nb})$ phase in which three $U$ atoms occupy the $(0,0,0)$, $(0,5 / 6,1 / 2)$, and $(1 / 2,1 / 3,1 / 2)$ lattice sites; one $\mathrm{Nb}$ atom occupies the $(1 / 2,1 / 2,0)$ lattice site. The $U_{3} \mathrm{Nb}$ phase is likely a metastable phase since it does not exist on the equilibrium U-Nb phase diagram. A further study is required to understand its phase stability. 

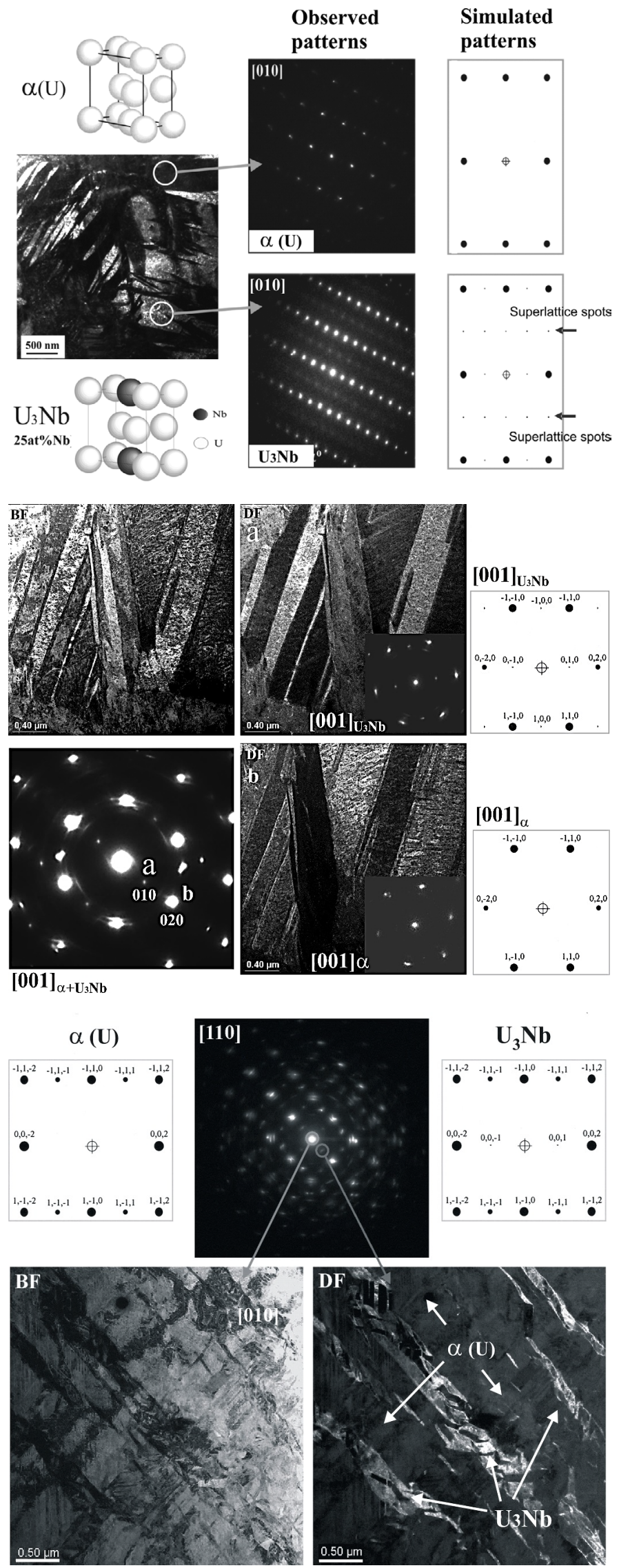

Figure 9: TEM analyses of $\mathrm{Nb}$-depleted $\alpha(\mathrm{U})$ phase and $\mathrm{U}_{3} \mathrm{Nb}$ phase formed after accelerated aging of 15-yearold alloy at $200{ }^{\circ} \mathrm{C}$ for 96 hours. SAD patterns and simulated diffraction patterns are generated from: a) The [010]-zone; b) The [001]-zone; and c) The [110]-zone. 


\section{Stress-strain behavior of acceleratedly aged 15-year-old WQ alloy}

Tensile stress-strain curves obtained under a quasi-static loading condition for the 15-year-old $W Q$ alloy and the same alloy acceleratedly aged at $200{ }^{\circ} \mathrm{C}$ for 2 hours $(2 \mathrm{~h}$ ) and 96 hours ( $96 \mathrm{~h}$ ) are shown in Figure 10. The stress-strain behavior clearly reveals the occurrence of age strengthening in the 15-year-old WQ alloy acceleratedly aged at $200{ }^{\circ} \mathrm{C}$, which is consistent with the occurrence of age hardening in the acceleratedly aged 15-yearold WQ alloy measured by microhardness method (Figure 1). The ultimate strength continuously increases from $\sim 121 \mathrm{ksi}$ at $200{ }^{\circ} \mathrm{C} / 0 \mathrm{~h}$, to $\sim 124 \mathrm{ksi}$ at $200^{\circ} \mathrm{C} / 2 \mathrm{~h}$, and to $\sim 135 \mathrm{ksi}$ at $200{ }^{\circ} \mathrm{C} / 96 \mathrm{~h}$; whereas the ductility continuously decreases from $\sim 0.3$ at $200{ }^{\circ} \mathrm{C} / 0 \mathrm{~h}$, to $\sim 0.28$ at $200{ }^{\circ} \mathrm{C} / 2 \mathrm{~h}$, and to $\sim 0.15$ at $200{ }^{\circ} \mathrm{C} / 96 \mathrm{~h}$ because of the age strengthening.

\section{Discussion}

While low-temperature age hardening was observed from both as-water-quenched and 15-yearold WQ alloys (see Figure 1), a much longer aging time was required to reach hardness peak for the 15-year-old alloy. This discrepancy can be rationalized by different aging mechanisms occurred in these two alloys. The age hardening of as-waterquenched alloy is caused by spinodal decomposition: A modulated structure with a wavelength of $3 \mathrm{~nm}$ is developed along the $[001]_{\alpha^{\prime \prime}}$ direction. The age hardening of 15 -year-old WQ alloy is caused by chemical ordering and precipitation. The occurrence of chemical ordering in the 15 -year-old WQ alloy results in the formation of swirl-shaped antiphase domain boundaries (APBs) in the ordered $\alpha$ " martensitic phase. Through the crystallographic simulation framework demonstrated in Figure 7 and Figure 8 , it is suggested that the ordered $\alpha^{\prime \prime}$ martensite can be generated from a spinodal modulation along the [001] direction with the modulation wavelength $(\lambda \approx 0.5 \mathrm{~nm})$ which is equal to the distance between two (001) planes, as illustrated in Figure 11. Note that the modulation wavelength at ambient temperatures is approximately an order of magnitude smaller than the wavelength of spinodal modulation occurred at $200{ }^{\circ} \mathrm{C}$. This temperature-dependence of spinodal modulation, i.e. the modulation wavelength decreases with decreasing temperature, agrees with the phenomenological theory of spinodal decomposition [12]. The formation of such an atomic scale modulation can be attributed to low thermal energy at ambient temperatures, which makes atoms difficult to migrate over a long distance. Instead, the atoms exchange their positions more effectively with their neighboring atoms. When the same species of atoms move to the same atomic planes, an atomic-scale modulation forms and the supersaturated $\alpha^{\prime \prime}$ phase becomes chemically ordered. Such modulation and chemical ordering help to reduce the free energy of the supersaturated solid solution. At elevated temperatures $\left(200^{\circ} \mathrm{C}\right)$, higher thermal energy enables atoms to diffuse over relatively longer distances, which leads to the formation of modulated structures with a longer wavelength $(\lambda \approx 3 \mathrm{~nm})$. Compared to the atomic modulation formed at ambient temperatures, the modulated structure with longer wavelength has fewer interfaces. Thus, the longer wavelength modulation is an energy-favored modulation at elevated temperatures.

Two types of continuous transformations were observed to occur in WQ-U6Nb alloy at two different temperatures, i.e., continuous ordering $(\lambda \approx 0.5$ $\mathrm{nm})$ at ambient temperature and spinodal decomposition ( $\approx 3 \mathrm{~nm}$ ) at $200^{\circ} \mathrm{C}$. These low-temperature transformations reveal that the supersaturated solid solution in WQ-U6Nb alloy is thermodynamically unstable and is prone to cause composition fluctuations propagating along the $[001]_{\alpha^{\prime \prime}}$ direction, and the wavelength of the composition waves is dependent on the aging temperatures. For thermal aging of $\mathrm{WQ}-\mathrm{U} 6 \mathrm{Nb}$ alloy at $200{ }^{\circ} \mathrm{C}$, the transformation rate is fast, and the transformation sequence is: Disordered solid solution $\alpha^{\prime \prime} \rightarrow$ spinodal decomposition $\rightarrow \alpha_{1}$ (Nb-lean) $+\alpha_{2}$ (Nb-enriched). For ambient-temperature aging of WQ-U6Nb alloy, the transformation rate is sluggish, and the transformation sequence is disordered $\alpha^{\prime \prime} \rightarrow$ continuous ordering $\rightarrow$ ordered $\alpha^{\prime \prime}$. For accelerated aging of ordered WQ-U6Nb alloy at $200{ }^{\circ} \mathrm{C}$ and $212{ }^{\circ} \mathrm{C}$, the transformation sequence is ordered $\alpha^{\prime \prime} \rightarrow$ phase decomposition $\rightarrow \mathrm{Nb}$-depleted $\alpha(\mathrm{U})+\mathrm{Nb}$-enriched ordered phase. It can be readily seen from Figure 10 that the age strengthening associated with the strength increase and the ductility reduction occurred presumably due to the precipitation of ordered $\mathrm{U}_{3} \mathrm{Nb}$ phase, and the ductility of the 15-yearold WQ alloy reduced by $50 \%$ from $\sim 0.3$ to $\sim 0.15$ after acceleratedly aged at $200{ }^{\circ} \mathrm{C}$ for 96 hours.

\section{Conclusions}

Low-temperature aging mechanisms of WQ- 


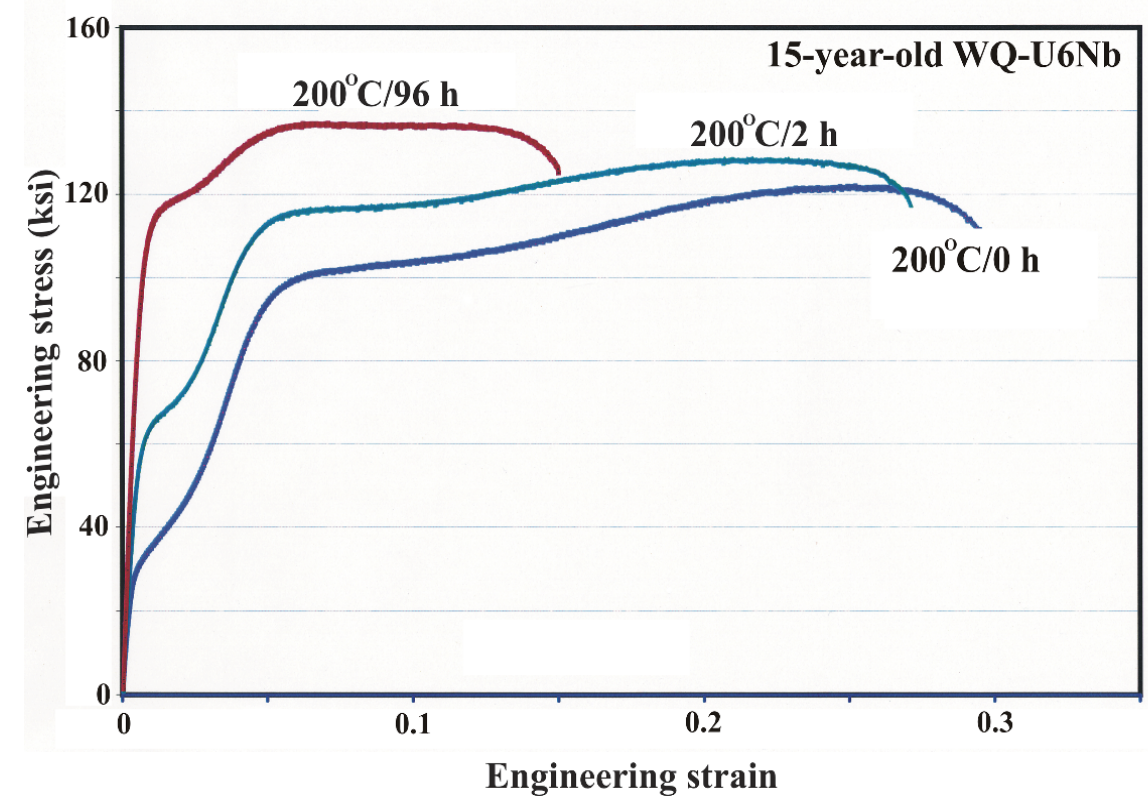

Figure 10: Tensile stress-strain curves obtained under a quasi-static loading condition for the 15-year-old WQ alloy acceleratedly aged at $200^{\circ} \mathrm{C}$ for 0 hour $(0 \mathrm{~h}), 2$ hours $(2 \mathrm{~h})$, and 96 hours (96 h) respectively.

Supersaturated $\alpha^{\prime \prime}$ solid solution

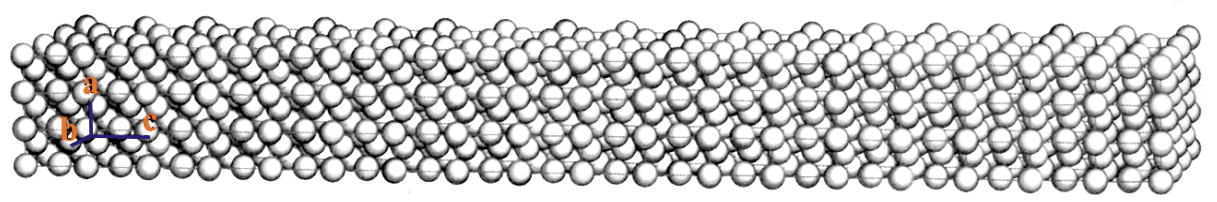

Spinodal decomposition at $200{ }^{\circ} \mathrm{C}$

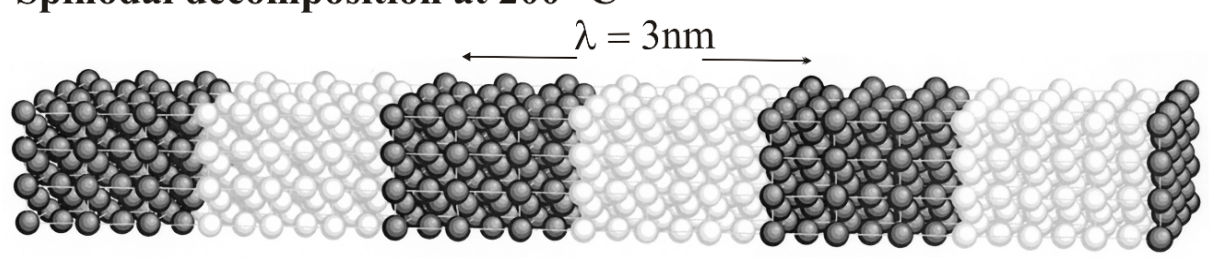

Ordering transformation at ambient temperatures

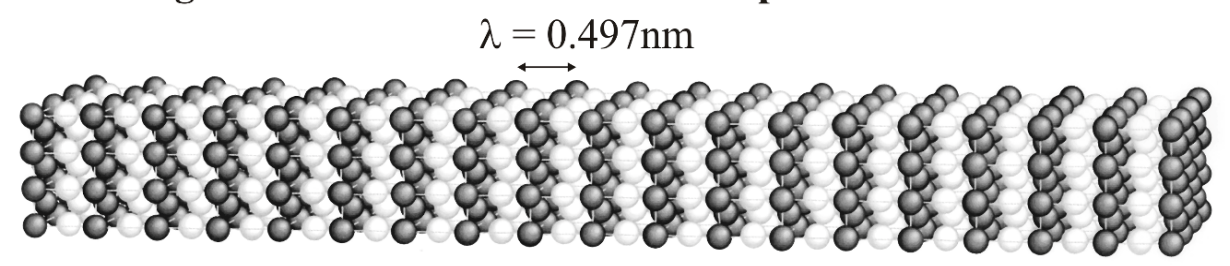

Figure 11: Schematic illustrations show the temperature dependence of the wavelength of spinodal modulation, in which the dark spheres represent the $\mathrm{Nb}$-enriched atomic positions.

U6Nb have been investigated using both as-water-quenched and 15-year-old WQ alloy samples. Microstructure and microhardness changes during thermal aging of the as-water-quenched WQ alloy at $200^{\circ} \mathrm{C}$ and thermal aging of the 15 -year-old WQ alloy at $200^{\circ} \mathrm{C}$ and $212^{\circ} \mathrm{C}$ have been studied. Transformation sequences were proposed to rationalize low-temperature aging mechanisms of WQ-U6Nb alloy. The age hardening behavior observed from thermally aged as-water-quenched alloy can be attributed to the occurrence of spinodal decomposition: $\alpha^{\prime \prime} \rightarrow \alpha_{1}$ (Nb-lean) $+\alpha_{2}$ (Nb-enriched). A composition wave propagating along the [001] ${ }_{\alpha^{\prime \prime}}$ direction with the wavelength $\lambda \approx 3 \mathrm{~nm}$ took place during 
the spinodal decomposition. A continuous ordering reaction: Disordered solid solution $\alpha^{\prime \prime} \rightarrow$ ordered $\alpha^{\prime \prime}$ took place during the ambient-temperature aging of WQ alloy, which can be attributed to an atomic-scale composition wave propagating along the [001 $_{\alpha^{\prime \prime}}$ direction with the wavelength $\lambda \approx 0.5 \mathrm{~nm}$. During accelerated aging of the 15-year-old WQ alloy at $200^{\circ} \mathrm{C}$ and $212^{\circ} \mathrm{C}$, the ordered $\alpha^{\prime \prime}$ martensite further decomposed into a $\mathrm{Nb}$-depleted $\alpha$ phase and a $\mathrm{Nb}$-enriched ordered phase which led to the increase of microhardness over an aging duration of 240 hours at $200{ }^{\circ} \mathrm{C}$ and 96 hours at $212^{\circ} \mathrm{C}$. The tensile strength increased from $\sim 121 \mathrm{ksi}$ to $\sim 135$ $\mathrm{ksi}$, whereas the tensile ductility reduced from $\sim 0.3$ to 0.15 after accelerated aging of the 15-year-old WQ alloy at $200^{\circ} \mathrm{C}$ for 96 hours because of the precipitation of a $\mathrm{Nb}$-enriched ordered phase.

\section{Acknowledgements}

This work was performed under the auspices of the U.S. Department of Energy by Lawrence Livermore National Laboratory under Contract DEAC52-07NA27344. The authors gratefully acknowledge T. C. Sun for the work of tensile testing and Vicki Mason-Reed for the work of microhardness measurements.

\section{References}

1. J Koike, ME Kassner, RE Tate, RS Rosen (1998) The $\mathrm{Nb}-\mathrm{U}$ (niobium-uranium) system. Journal of Phase Equilibrium 19: 253-260.

2. KH Eckelmeyer, AD Romig, LJ Weirick (1984) The effects of quench rate on the microstructure, mechanical properties, and corrosion behavior of U- $6 \mathrm{Wt}$ Pct Nb. Metallurgical Transactions A- Physical Metallurgy and Materials Science 15: 1319-1330.

3. RA Vandermeer (1980) Phase transformations in a uranium +14 at.\% niobium alloy. Acta Metall 28: 383-393.

4. G Beverini, DV Edmonds (1989) An APFIM study of the aging behavior of U- 6 wt-percent $\mathrm{Nb}$. Journal De Physique 50: 429-434.

5. D Kelly, JA Lillard, WL Manner, R Hanrahan, MT Paffett (2001) Surface characterization of oxidative corrosion of U-Nb alloys. Journal of Vaccum Science \& Technology 19: 1959-1964.

6. RA Vandermeer, JC Ogle, WG Northcutt (1981) A phenomenological study of the shape memory effect in polycrystal uranium niobium alloys. Metallurgical Transactions A 12: 733-741.

7. RD Field, DW Brown, DJ Thomas (2005) Texture development and deformation mechanisms during uniaxial straining of U-Nb shape-memory alloys. Philosophical Magazine 85: 1441-1457.

8. RJ Jackson, RP Brugger, DV Miley (1968) Tensile properties of gamma quenched and aged uramiumbased niobium alloys. ASM Transactions 61: 336-343.

9. K Orlov, VM Teplinskaya, NT Chebotarev (2000) Decomposition of a metastable solid solution in uranium-molybdenum alloy. Atomic Energy 88: 43-48.

10.JC Zhao, MR Notis (1999) Ordering transformation and spinodal decomposition in Au-Ni alloys. Metallurgical and Materials Transactions 30: 707-716.

11.J Zhou, L Hsiung (2006) Long-term phase instability in a water-quenched uranium alloy. J of Materials Research 21: 904-909.

12.JW Cahn (1968) Spinodal decomposition. Transaction of TMS and AIME 242: 166-180.

13.JW Edington (1976) Practical electron microscopy in materials science. In: Van Nostrand Reinhold, New York, USA.

14.PB Hirsch, A Howie, PB Nicholson, DW Pashley, MJ Whelan (1967) Electron microscopy of thin crystals, Butterworths, London, UK.

15.WA Soffa, DE Laughlin (1982) Solid-state phase transformations. In: HI Aaronson, AIME Warrendale, The Pittsburg Conference, PA, USA, 159-183. 